mention, in his estimation of the mortality from disease, the number of attacks to which persons in different ages of life were subjected. Measles and scarlet fever were diseases usually of early life, but it had been shown that when measles attacked adult persons it was comparatively more fatal than in earlier periods of existence. An epidemic of measles occurred at the Cape of Good Hope some time since, the disease not having appeared in that colony for nearly twenty-five years previously. The adult persons who were attacked suffered most severely from the disease, and one-third of them fell victims to it. The same rule held good with regard to scarlet fever. That disease was no doubt, as a rule, more fatal and malignant in fat and well-fed than in thin, spare children. He agreed with the statement of the author, that fever was more prevalent in agricultural districts than in towns; but this arose from the labourers generally living in huts with mud floors, the exhalations from which would be most prejudicial to health. The agricultural labourer also experienced the great disadvantage of an inadequate supply of pure water, which was obtained generally from neighbouring rills or small rivers, which contained the exuviæ of the inhabitants.

Dr. Murchison said that the author of the paper had lost sight in his calculation of a most important fact : he had not given the relative mortality in comparison to the prevalence of disease. The fatality had often no reference whatever to the number of attacks. The mortality compared with the prevalence of disease was different at different times in different epidemics, even in the same year, and in different places, consequently no just conclusions could be drawn from the statistics advanced in the paper. Under the head of fever, various diseases were classed together in the Registrar-General's reports, and, as Dr. Farr well knew, no conclusions conld be drawn from these documents. Under the head of typhus very distinct forms of disease were classed together, and hence arose a most dangerous fallacy as to the amount of mortality from this malady. $\mathrm{He}$ denied that typhus was to be classed as an endemic disease Typhoid fever, no doubt, was endemic, whilst typhus, on the contrary, was essentially epidemic. True typhus fever had been almost absent from London for the last six months. No case of typhus fever had been admitted during that period into the Fever Hospital, and in the other hospitals the cases of fever were of the typhoid kind. He referred to a paper which he had read during the last session of the Society, "On Typhus and Typhoid Fevers." He would therefore not enter more fully into the discussion of these maladies, inasmuch as in the forthcoming volume of the "Transactions" his views would be open to the investigation of the fellows, and they would there learn the conclusions at which he had arrived.

Dr. A. P. STEWART said that the author of the paper was of opinion that fevers were all of the same type, but in this he was certainly wrong. Typhus fever was epidemic; typhoid fever was endemic. He had been struck with the gravity and mortality of scarlet fever amongst the higher orders, whilst amongst the poor its gravity and mortality were very much less. With respect to the prevalence of small-pox in Devonshire, this was explained by the general practice of inoculation, which created an artificial epidemic, and a consequent mortality.

Dr. Burrows agreed with Drs. Copland and Murchison resperting the deficiency in the paper of the comparative mortality taken with reference to the frequency of the attacks of the disease at different ages. He differed with the author of the paper respecting the conclusions he had drawn regarding the mortality of fevers. The author had confounded severa diseases together, and hence the conclusions at which he had arrived were not to be relied upon. He (Dr. Burrows) corroborated the statement of Dr. Murchison, as to the infrequency of continued fever in London during the first nine months of the present year. In St. Bartholomew's Hospital, from Christmas last to the 1st of September, not more than one or two cases of typhus fever had been admitted into that institution in the course of a single month. Since that time the wards had been full of cases of fever, but they were of the typhoid kind. He did not wish to use any harsh expression, but he must say that, if the conclusions of the author were to be receiver, they would establish error, and not support truth.

Dr. WiLson remarked that the statements which had been made that evening offered a striking commentary on the panic which had seized upon all classes of persons in the metropolis resp=cting the state of the public health during the greate portion of the year. It was proved incontestably that, notwithstanding the state of the Thames, the diseases to which its pollution was assumed to give rise were never less prevalent than during the period of its worst condition. (Hear, hear.)

\section{MEDICAL SOCIETY OF LONDON.}

Monday, Nor. 15 Tr, 1858.

Dr. Willshire, Prestdext, m the Chiar.

MIr. BAKER Browy related the two following cases :-

L. $\mathrm{P}-$ - aged twenty, married two years; no children. Soon after marriage she noticed an increase of abdomen, which went on until March, 18.58, when she had an attack of peritonitis. This was subdued, but she soon relapsed. After varions remedies, she was admitted into the "London Home" on October 12th. Mnltilocular ovarian dropsy, with adhesions on the anterior and lower part, was diagnosed. On October 20 th, Mr. Baker Brown proceeded to operate. He made an incision from the navel to the pubes, and removed a cyst weighing about fonrteen pounds. The adhesions were numerous, but were easily broken down. The pedicle was secured by a clanap fixed externally. The wound healed by first intention as far as the pedicle, and the patient up to the present time has not had a single bad symptom.

A. P-, single, aged twenty-six, perceived a swelling low down in the right side, which at first increased rapidly, but afterwards more slowly. After various remedies, she was placed under Mr. Jackson, of Sheffield, who discovered ovarian dropsy, and recommended her to Mr. Brown's care. He discovered multilocular ovarian dropsy withont adhesions. After proper preparations, Mr. Brown proceeded to operate, and made an incision from the navel to the pubes, and removed a cyst weighing upwards of $22 \mathrm{lbs}$. On puncturing, a large quantity of fluid escaped, and the walls of the tumour were so rotten as to be broken down with very slight pressure. The pedicle was secured by a clamp fixed externally. As in the previous case, the wound healed by first intention as far as the pedicle, and up to the present time the patient has not had a single bad symptom.

Mr. BAKEe Brown also showed a new instrument invented by his colleague, Mr. Philip H. Harper, for securing the pedicle in ovariotomy. It consists of two flat blades, three inches and a half long, without the handles, and united by an easily-moving joint at one end. Each blade is half an inch in breadth, and a quarter in thickness. The inner surface of one is concave, and of the other convex. The convexity is so worked as to fit into the concavity of the former. At a distance of two inches and a half from the joint is fixed a slightly-curved bar, with saw teeth on the external side; this bar passes through an opening made in the opposite blade, worked into a rack-catch, so that the teeth of the bar lock into it. On the external edge of this opening is fixed a steel spring, which, when the bar is passed through, presses it upon the rack, so that it cannot slip or move without being pressed back. The handles, which are removable at pleasure, are strong, and about five inches long. The action is very simple. The blades being opened wide, and the pedicle pressed in between them and the cross bar, are then closed, and brought tightly together. The pedicle is thus bruised without being cut, and all chance of hæmorrhage prevented. The bandles are then removed, and the clamp itself left on. It can be easily taken off whenever it may be con. sidered adrisable.

Mr. HuTcmisson remarked that he thonght we could scarcely lay too great stress on the importance of bringing the extremity of the divided pedicle out of the wound. This was the grand improvement in ovariotomy. He believed that it might, by proper measures, be accomplished in almost all cases, and that if it were, we might, without unfairness, throw aside all statistical calculations of the mortality of the operation on the old plan. Without doubt, the easiest and quickest mode of securing the pedicle was by means of the steel clamp, which he had himself been the first to use, and of which he was glad to hear that Mr. Brown so highly approved. There were cases, however, in which, from the shortness of the pedicle, its use would be inconvenient. In each he would advise the operator to put on a single whipcord ligature, and then cut into the tumour itself so as to leave a considerable portion by which to prevent the end from slipping of. It would not then be necessary that the ligature should be brought to a level with the skin, as the purpose would be gained if it were only kept above that of the peritoneum. He adverted also to other manœuvres by which a short pedicle might be yet brought out externally. To prevent hæmorrhage from adhesions he would advise, in the first place, that no cutting instrument should be employed in the separation of the latter; and, secondly, that any bleediug vessels should be compressed by means of peculiar forceps contrived by Mr. Webber for that 
purpose. These forceps are made with a bluntish edge, by which the internal and middle coats of an artery are divided, the external being left entire. Mr. Hutchinson exhibited these forceps to the meeting, and also a very large trocar which he had had made for the purpose of rapidly emptyirg the cyst. The canula had a diameter of five-eighths of an inch, and was fitted with an india-rubber tube, by which not only was the escape of fluid into the peritoneal cavity prevented, but the necessity of basins, \&c., being held in the operator's way, was obviated. With this instrument, a cyst, which would take ten minutes to empty by the largest trocar in ordinary use, might be emptied in a minute or two-a point of great importance in an operation in which the time during which the peritoneum is exposed constitutes a large element of risk. With regard to the best material for clearing out any blood or cyst-contents which have escaped into the abdominal cavity, Mr. Hutchinson believed that scalded sponge would be founcl much more efficient than flannel, and much less irritating and softer than sponge in its ordinary state. The operation was one in which everything depended upon attention to details.

\section{N1r. BiRweLL read a paper}

\section{ON THE HTSTERIC CONDITION OF JOINTS.}

These affections, the author observed, are not rare, especially amongst the more luxurious classes, and they have often been mistaken for actual joint disenses, when blisters and issues, increasing the evil, have been applied, or even more heroic and disastrous treatment adopted. It wust be confessed that the literature of the subject, and the cases collected, are meagre and unsatisfactory, and, therefore, tbis paper is intended to present a concise, yet detailed sketch of the disease, and of some new points in its treatment.

Although in a malady so Protean as hysteria no short description of invariable symptoms can be given, yet two peculiarities may be fixed upon as especially characteristic; and these are, the absence of the ordinary signs of inflammation and "anomaly." One may be inclined to add to these symptoms, the hysteric condition, yet though su $\mathrm{h}$ condition is present in many cases, yet it is in others quite absent, or so sliglbtly marked as hardly to exceed the ordinary mobility of the feminine character. When hysteria breaks out in the paroxysm, it is usually sated by that manifestation, and produces no such serious effects as a pseudo-malady; indeed, the imitative tendency of hysteria is often checked by a regular fit, and a simulated disease may occasionally thus end; but, in other cases, the imitation may continue uninterrupted by any other hysteric symptom, and we are then thrown for our diagnosis upon a purely local investigation. Let us first take the knee as the more frequently affected joint. The pain is, in some cases, so severe as to make the patient hold her leg constantly semi-flexed and immovable; in other cases it is so slight that the patient, though complaining, walks about. The pain is not in direct, but rather in inverse ratio with any other hyste. rical symptom. It may be increased at the menstrual period. It is generally referred to a spot on either side of the limamentum patellæ, and is increased on the slightest touch at this spot, but especially if a piece of the subcataneous fat here situated be pinched. In other cases, the tenderness is spread over a larger space, but is always superficial. The articulating surfaces are not tender; they may be forced together by pressing the foot npward, without yroducing pain. In the severer cases, when the knee is kept fixed, the surgeon, if he attempt to change its position, will feel the muscles of the limb thrown into strong action. A striking characteristic is the absence of heat about the affected joint-it feels quite as cool, and sometimes, the author is inclined to think, eren cooler than the other. Swelling, in any marked degree, is absent in cases of knee-joint disease; if measurements be taken, the swelling will be found greater than is ordinarily supposed; but the hysteric knee, when not inflamed by irritant tratment, is seldom swollen, and never more than about three quarters of an inch. The swelling is tegumentary merely; the healthy parts may be felt beneath.

When the disease affects the hip, it is, by a skilful eye, even more easily detected. When the patient is lying down, the limb is drawn up, the knee bent, and there is great superficial tenderness over the whole haunch, hip, and thigh, but no pain on pressing the articular surfaces together from the heel upwards; if the joint be not moved, there is no greater heat on that side than on the other. If the surgeon, by perseverance, get his patient to stand, he will observe a marked twisting of the pelvis, in part an imitation, in part exargeration, of the position assumed in hip disease. The glutei may be felt in strong action, and the nates, instead of being flat, on that side are protuberant. Swelling is hardly to be measured at the hip, because it is surrounded by muscles whose greater or less action must alter the dinensions of the part. That creaking of certain joints which sometimes comes on with puberty may gradually become more fixed, till it settle down into hysteric joint disease; therefore there sometimes accompanies this malady a parchment-like crepitation, which is easily distinguished from the crepitus of rheumatic arthritis. Besides these signs, it must be remarked that an hysteric patient has not the worn aspect of one whose cartilages are ulcerating.

Now the peculiarities of hysteric disease impress upon the local complaint a quality of unreality which requires some examination. It is not to be supposed that these patients willingly deceive their medical attendant, nor that the pain complained of has no real existence; but it is not produced by a local con. dition - the malad $y$ is centric, not excentric. Hysteria has, perhaps, been too much regarded as the bette noire of medicine, connected with an obscure and sometimes undiscoverable menstrual disorder; and therefore to be treated with iron and emmenagogues and such-like medicines. Yet, in truth, though the disease may be originally proluced by the circumstances and conditions of woman's life, it soon becomes independent of uterine action or inaction; it becomes a neuropathy which can be called forth by the feelings and imaginings of the patient, who is more or less aware of the power she exercises over her condition, and, believing her sufferings real, is yet delighted to direct them by such mental acts. Thus the malady must be treated on other principles than stich as wonld follow a mere uterine pathology. Great harm is done by the indiscriminate use of steel, ethers, aloes, \&c., which are often given when a lower diet and more exercise would much better. cure the disease. If however, the above view be correct, the treatment must rather be directed to the cerebral condition which prodnces the neuralgia-like pain, and which has the faculty of swaying the disease by its own enotional state; for it must be evident from that view, that if this emotional state can itself be dominated, the disease will be governed with it; if the patient's faith can be so far mastered as that she shall fully expect to be cureci by any yiven proceeding at a certain time, she will be cured by that method at the time specified. The anthor has tried several means whereby the patients' confidence having been sufficiently gained, he coull call away their attention from the part affected to some distant spot, in which a disorder working its own cure had been artificially produced. Of all such means, a seton seems in most instances the best; this is to be made of a single ligature (silk) set in at a distance from the affected joint, and embracing only a small portion of skin. The placing of a seton is sufficiently painful and like a surgical operation to attract strongly the patient's attention, and yet not so much so as to be cruel or greatly repugnant to her feelings. Another advantage is that, besides a distinct beginning, it has a certain end, which the patient is to watch; and if she helieve, as can well be managed, that as the seton works through the slin she will get better, and when it comes quite away she will be well, the result is certain to follow her belief. Mr. Barwell read several cases which he had thus treated, and quoted in supnort a case in which Mr. Hancock, by giving a patient thus affected chloroform, and performing a mock operation, had produced a cure. He observed, in conclusion, that the most essential points were-to be quite certain in the diagnosis, to master the confidence of the patient, and to place the seton or other agent at a sufficient distance from the part affected.

Mr. Bey ANT remarked that heat and swelling were occasionally present in hysterical affections of the joints. Indeed, in neuralgic affections generally, increase of heat and size were common symptoms. In the treatment of hysterical cases, he relied more upon constitutional than local remedies. The indication was clearly to remelly any deficiency in the state of the general health. The usual plan of treatment in Fuy's Hospital was the administration of the foetid gums. He objected to the employment of setons, except in very extreme cases, and mentioned an instance in which the patient died from pvæmia, in consequence of the introduction of a seton. He objected altogether to the nse of any sham operation, as unnecessary, and liable to be followed by mischief.

Mr. CAstox observed, that in most, if not in all, hysterical cases, if proper inquiries were made, some derangement would be found in the menstruil function, either in regard to quantity or quality. There would usually be a profuse discharge of pale urine, and a peculiarity in the apnetite, and otber symptoms diagnostic of the hysterical condition. The treatment pursued must be with a view to improve the general health. He also 
alluded to the absence of pain in hysterical patients, when the attention of the sufferer was directed to another object, when pressure was made over the affected joint.

Dr. CAMPS considered that a difference between neuralgia and hysteria was sufficiently marked. In the first, the symptoms were dependent upon a morbid condition of the nerves of the part; in the second, they arose from the brain In the first, there might be heat and redness; in the second, these symptoms were generally absent.

Dr. WiLrSHIRE observed, that when heat and swelling were present in cases of hrsteria, there was something in addition to the hysterical condition present. Neuralgia was of excentric origin. It might be dependent upon inflammation of the nerve or its covering, or the irritation of a spicula of bone, or other local causes. Hysteria was developed from centric causes.

Dr. HEADLAND ridiculed the performance of an operation, or the introduction of a seton, in hysteria, as means calculated still further to direct the patient's attention to the part affected. The treatment must be mainly directed to the constitutional condition of the patient.

Mr. WEEDEN COOK recommended the use of friction and cold affusion in hysterical joints, and thought that operations were not justitiable.

Mr. Duns, jun., considered that heat and swelling were not symptoms of hysteria, but of neuralgia, and related an instance to show the effect of mental impressions upon the production of hysterical symptoms.

Dr. OGIER WARD mentioned an instance recorded in the "Life of Sir H. Davy," illustrative of the power of the mind in curing disease. A man affected with paralysis, in the course of experiments, had a thermometer placed under his tongue on several successive occasions, and was eventually cured.

Mr. Barwell having replied, the Society adjourned.

\section{WESTERN MEDICAL AND SURGICAL SOCIETY. Friday, OCTOBER 22ND, 1858.}

\section{A. B. Barnes, Esq., Presment, in the Chair.}

AFTER the transaction of the ordinary routine business, the President opened the session by making a few introductory remarks upon the objects and advantages of the Society. He then passed on to the different medical subjects of the day, alluding especially to the Medical Act, which has so lately become the law of the land. He considered that much good might eventually come from it, if the profession proved true to itself, and was tenacious of its own rights and honour. He called upon the profession to prove itself an united body, and not to offer to the public the disreputable aspect of being divided into numerous parties, each jealous of the other, and offering opposition to each other's movements, all of which, if properly directed, should have but one object in view-namely, the common weal of the community at large. After remarking upon the necessity there was for every member of the profession to act from the highest motives, he observed that the opinion the public formed of us entirely depended upon our. selves and our actions, and as such was the case, he thought that we should support one another in all difficulties, and on all occasions when no contrary principle was involved. The present efficient state of the library was then passed in review, and its increasing value extolled as a great boon to the members of the Society. It numberel several hundred volumes, all of which were available for home use. The late Warrant for the Army Medical Service was then alluded to, and its appearance hailed as a great boon, and as but a just reward in appreciation of the services of the medical officers; this justice, though late, was very welcome, and tended to make them in no way inferior to that of the combatant portion of the army in the estimation of the public.

Dr. BAINes then read a paper,

ON DELIRIUM, ESPECIALLY IN TTS RELATION TO FEYER AND PERICARDITIS.

Commencing with a few introluctory remarks respecting the difficulty of clearly defining delirium, and placing the boundary line between it and rational action of the mind, he sketched the chief mental phenomena which are generally observable in cases where the mind becomes aberrant. stating that the regulating power of the reason was absent in all cases of delirium, and that the ideas in the mind ran together in confusion and unconnectedness. He drew an analogy between it and dream ing, adopting Dr. Pritchard's itlea, that delirium " is a species of dreaming, only more profound." Passing from the psychology of the subject, he alluded to the more practical application of $1 t$, and recognised the various states and circumstances of the system in which the symptom is likely to occur, and specialized that occurring in insanity and in delirium tremens. The symptoms accompanying its occurrence were briefly alluded to, and each state of brain, where the blood is in excess or in deficiency, received its share of attention. The convulsions, or muscular movements, too, which were often present, were discussed, especially as they tended, by their continuance, to exhaust the vital energy of the patient.

Delirium was classified as of two kinds. 1. Where it depended upon, and was associated with, increased or decreased vascular action only. In these cases the symptom will, of course, vary according to the state of the brain, as regards the quantity of blood circulating in it. If congestion be present, the whole system will be in a state of muscular and nervous exaltation, and the delirium probably very violent and maniacal; on the contrary, in the other state of the system it will be associated with an exhausted state of nervous and vital energy. 2. Where it is dependent upon, and associated with, some toxic element circulating in the blood, as occurs during the progress of typhus, and all fevers of the specific kind. In these cases the toxæmia was the fons et origo mali, and recognising that fact, our endeavours must regard the general system rather than the symptom. How the poison in the blood acts, whether by directly exciting the brain-matter to action, or by exciting some molecular change in the nerve vesicles, it was impossible to state; we were only able to recognise the symptom as due to this poison, and therefore were called upon to rally the system while under its influence.

The principles of treatment and the morbid appearances were briefly sketched, and much attention was drawn to the fact of the false, or pseudo morbid signs often seen after death, which appearances were often due to post-mortem changes in the vessels, and often depended, not upon inflammatory action during life, but upon the mode of dying, or upon some organic change taking place immediately after death.

The occurrence of delirium in typhus was then especially entered upon, and its nature discussed. It was regarded as due to the blood-poisoning in the majority of cases, though in a few, even in fever, it might be caused by an inflammatory condition of the brain and its membranes. The difficulty of recognising its true cause was alluded to, and Dr. Graves'admirable observations on this subject mentioned. What is the true action of the fever poison on the brain-matter? The answer involved in this question was too extensive to receive more than a general notice. It might be that several elements were at work to produce the one prominent result; it might be that the poison effected some alteration in the relations between certain parts of the brain, or by its actual presence acted as an irritant to the nervous matter, exciting in it increased action in certain parts, and exercising a paralysing effect on other controlling portions; or, perhaps, the poison might so far alter the physical character of the blood as to render it more or less incapable of flowing freely through the capillaries. All these speculations open out yet more extensive fields of inquiry, embracing, as they do, the normal rate of circulation necessary for healthy action of the brain; the degree of arterialization which is essential for the same, and how far it is interfered with in these cases; and the part which the retention of carbonic acid in the blood (all the vital functions, especially respiration, being lowered) takes in the development of the delirium. Leaving the speculative part of the subject, the application of remedies next called for attention, and the general subject of wine and opium entered upon, the objects to be borne in mind being to support the strength during the continuance of the fever, and to calin the restless action of the nervous system.

In pericarditis the occurrence of delirium was an important event, inasmuch as it often suddenly set in, and betokened much danger. Post-mortem appearances, and general careful observation during life have recognised this symptom to be dependent upon a deficient supply of blood to the brain, and to be indicative of exhaustion in a large majority of cases; in three, quoted by Dr. Watson, it was found in connexion with unequivocal signs of inflammatory action in the brain. It generally occurs in rheumatic pexicarditis; though, out of sixteen cases quoted by Dr. Burrows, there was evidence of rhenmatism only in seven. It may be developed also during endocarditis, which circumstance may afford a link to the probable expla. nation offered of its dependence upon a deficient or irregular supply of blood to the brain, caused by weakened or oppressed heart-action. Is that, then, its only possible explanation? Metastasis in a very few cases may possibly be ths canse, as seems 